\title{
Ultrasound Guided Port-A-Cath Implantation
}

\author{
Hossein Hemmati ${ }^{*}$, Mohammad Sadegh Esmaeli Delshad1, Mohammad Reza Barzegar1, \\ Ali Babaei Jandaghi², Behruz Najafi ${ }^{3}$, Mohammad Reza Asgary ${ }^{1}$, Acieh Es-Haghi' \\ ${ }^{1}$ Division of Vascular Surgery, Department of Surgery Razi Hospital, Guilan University of Medical Sciences, \\ Rasht, Iran \\ ${ }^{2}$ Departement of Radiology, Poursina Hospital, Guilan University of Medical Sciences, Rasht, Iran \\ ${ }^{3}$ Division of Oncology, Department of Internal Medicine, Razi Hospital, Guilan University of Medical Sciences, \\ Rasht, Iran \\ Email: *massahnias@yahoo.com
}

Received 25 February 2014; revised 20 March 2014; accepted 27 March 2014

Copyright @ 2014 by authors and Scientific Research Publishing Inc.

This work is licensed under the Creative Commons Attribution International License (CC BY). http://creativecommons.org/licenses/by/4.0/

(c) (i) Open Access

\section{Abstract}

Purpose: The use of port catheters is well accepted in the management of patients with malignancy. In this study, we compare the technical success and the complication rates of ultrasound guided Port-A-Cath implantation with doing this procedure by using the anatomical landmark method. Methods: In a retrospective study, from 2006 to 2009, medical files of 104 patients who had undergone Port-A-Cath implantation were reviewed. The indication for port catheter implantation was malignancy in all cases. Among our patients, Port-A-Cath implantation was done in 63 patients by using landmark method and in 41 patients by guidance of ultrasound. All patients had been observed for complications including pain, port infection, and port thrombus, thrombus of central veins, skin necrosis, and success in using of Port-A-Cath for at least one month following the procedure, in the vascular clinic. Results: in landmark method group, 2 catheters were nonfunctional just after placement (3.2\%) while all Port-A-Caths in ultrasound-guided group were functional. Ten patients $(15.9 \%)$ in land mark group and 1 patient $(2.4 \%)$ in ultrasound-guided group were complicated. The difference between complication rate in anatomic landmarks method and ultrasound-guided method was statistically significant $(p<0.04)$. There was no significant difference in two groups in duration of port placement $(p<0.345)$, age $(p<0.444)$, site of port placement $(p<0.244)$ or type of malignancy $(p<0.18)$. Conclusion: Considering high rate of success and low complications in placement of Port-A-Cath with ultrasound guidance, this method is superior to the land mark method in patients with malignancy.

\section{Keywords}

Ultrasound Guided, Port-A-Cath, Implantation

\footnotetext{
${ }^{*}$ Corresponding author.
} 


\section{Introduction}

By introducing different chemotherapeutic agents and considering complexities of anti-cancer treatment protocols, the need for reliable vascular access has significantly increased in two recent decades [1]. Patients with malignancy usually need repeated venipuncture for chemotherapeutic agents' injection, total parenteral nutrition, blood products transfusion and venous blood sampling. Therefore long-term, reliable central venous access is demanded in order to meet the requirements of multimodality intravenous therapy. Totally implantable port systems have been advocated to improve venous access reliably [2]-[7].

The care of oncologic patients has become much easier by the widespread use of Port-A-Caths for chemotherapy [8] [9]. Port-A-Cath devices were introduced into clinical practice of oncologic patients in 1982 [10]. Port-A-caths provide safe and long term access to central veins for chemotherapy [11]. Traditionally, Port-ACath is implanted by using anatomical signs on skin surface [12]. Therefore, it is essentially a blind process [13] which is with lower success and more complications [14]. Placement of port catheters by guidance of ultrasound was expressed in 1990s for the first time, which caused entrance of needle into the vessel with high accuracy [13]. Ultra sonography can be applied to evaluate the anatomic structures before attempting the puncture. Therefore, it increases rate of success [15] and decreases the complications [15] [16]. However, the use of ultra sound and the entrance of the catheter even in western countries are not much acceptable and are merely used partly [12].

Rate of complications related to Port-A-Cath is different from 5\% - 19\% considering the method of Port-ACath implantation [17]. These complications lead to increment in morbidity and mortality [18], increment of financial expenses because of long-term confining to bed, using antibiotics and replacement of catheter [19]. Therefore, minimizing and preventing complications should be common part of quality improvement program [12].

In recent years, surgery for implanting Port-A-Cath in patients who should be under consecutive and longterm treatments has been considered. Due to lack of enough study comparing the complications rate of Port-ACath implantation in two methods, we decided to assess the complications rate in two mentioned methods in a descriptive-comparative study in a three-year period (2006-2009), in order to have a strong base to suggest using ultrasound in Port-A-Cath implantation (as a reliable vascular access device) in oncologic patients.

\section{Materials and Methods}

In a retrospective study, from the year 2006 to 2009, medical files of 104 patients who had undergone Port-A-Cath implantation at Razi Hospital were reviewed. Indication for port catheter implantation was malignancy in all cases. Among our patients, Port-A-Cath implantation was done in 63 patients by using landmark method and in 41 patients by guidance of ultrasound. Internal jugular vein, preferentially on the right side, was our standard catheter access site. A triplex scan with portable ultrasonographic device (GE, LOGIQ Book) was used for determining the proper site for implantation. All patients had been observed for complications including pain, port infection, and port thrombus, thrombus of central veins, skin necrosis, and success in using of Port-A-Cath for at least one month following the procedure, in the vascular clinic. In this study, success in use of Port-A-Cath was defined in the form of ability in infusion therapy through Port-A-Cath.

The data was analyzed after entrance to SPSS-18 statistical software by using chi square, independent $\mathrm{T}$ and Mann-Whitney U tests. Also, descriptive statistics were offered in the form of abundance distribution tables and statistical indices (average and standard deviation). A statistically significant level was considered 0.05.

\section{Results}

In 104 patients, 63 had been implanted Port-A-Cath with anatomical landmarks while 41 patients with guidance of ultrasound. Among these, 17 patients were male (16.3\%) and 87 patients were female (83.7\%). Average age in landmark group and with ultrasound guidance was $49.38 \pm 12.2$ and $47.78 \pm 12.05$, respectively. Rate of breast cancer in both groups was more than other types of malignancy. Average port duration in group with anatomic landmarks and with ultrasound guidance was $11.05 \pm 6.99$ and $4.59 \pm 1.68$, respectively (Table 1). Port-A-Cath placement complications rate in both anatomic landmark and ultrasound guidance methods in breast cancer was more than other types of cancer (90\% and $100 \%$, respectively).

After Port-A-Cath placement, 2 catheters were non-functional just after placement (3.2\%) in anatomic landmark method group; while all Port-A-Caths placed in ultrasound-guided group were functional. Rate of success 
in anatomic landmark group was lower than second group, but this difference was not significant $\{61$ (96.8\%) vs. 41 (100\%), (p < 0.518)\} (Table 2).

Ten patients (15.9\%) in landmark group and 1 patient (2.4\%) in ultrasound-guided group were complicated. The most common complication in both groups was pain [6 (9.5\%) and 1 (2.4\%), respectively]. The difference between complications rate in anatomic landmarks method and ultrasound-guided method was statistically significant $(\mathrm{p}<0.04)$. No statistically significant difference was detected in types of complications between two groups (Table 2). In patients whose Port-A-Cath was placed in left or right subclavian veins by anatomic landmark method, no complication was detected. Complication rate of Port-A-Cath placement in left and right jugular veins in anatomic landmarks group was $25 \%$ and $15.2 \%$, respectively. In ultrasound-guided group, complication was only seen in patients whose Port-A-Cath was inserted in left jugular vein.

There was no significant difference in two groups in duration of port placement $(\mathrm{p}<0.345)$, age $(\mathrm{p}<0.444)$, site of port placement $(\mathrm{p}<0.244)$ or type of malignancy $(\mathrm{p}<0.18)$.

\section{Discussion and Conclusions}

Considering rate of various complications following administration of chemotherapeutic agents via peripheral veins in oncologic patients which are mainly related to the adverse effects of these agents at the site of injection, reliable access to the central vein is necessary [20]. For this reason, Port-A-Cath, as a safe vascular access, has an important role in daily care of patients suffering from cancer [6]. Cannulation of central vein by guidance of ultrasound has many advantages in comparison to anatomic landmarks [3]. Many researchers explained that sonographic imaging just before the catheterization of central vein makes selection of a proper vein possible [21]. Priority of ultrasound-guided catheterization is the decrease in number of needling. The recent studies have shown that different injections into any vein increases the risk for thrombus formation secondary to endothelial tissue damage during the procedure [22]. The results of different studies indicate the increase in success and decrease in occurrence of complications related to ultrasound-guided central vein catheter implantation [23]-[26].

Table 1. Distribution of demographic and clinical variables of patients.

\begin{tabular}{ccc}
\hline Variable & Anatomic Landmark Method (n= 63) & Ultrasound-Guidance method (n= 41) \\
\hline Age (year) & $49.38 \pm 12.2$ & $47.78 \pm 12.05$ \\
Sex (female/male ratio) & 49.14 & 38.3 \\
Duration of port placement (days) & $11.05 \pm 6.99$ & $4.59 \pm 1.68$ \\
Malignancy & & $30(73.52 \%)$ \\
Breast & $40(63.5 \%)$ & $6(14.6 \%)$ \\
Gastrointestinal & $11(17.5 \%)$ & $5(12.2 \%)$ \\
Other cases & $12(19 \%)$ & $31(75.6 \%)$ \\
Site of port placement & & $10(24.4 \%)$ \\
Right jugular & $46(73 \%)$ & - \\
Left jugular & $12(19 \%)$ & - \\
Right subclavian & $3(4.8 \%)$ & \\
Left subclavian & $2(3.2 \%)$ & \\
\hline
\end{tabular}

Table 2. Comparison of landmark with ultrasound-guided methods.

\begin{tabular}{|c|c|c|c|}
\hline Variable & Anatomic Landmark Method $(n=63)$ & Ultrasound-Guided method $(n=41)$ & P Value \\
\hline Rate of success & $61(96.8 \%)$ & $41(100 \%)$ & $0 / 518$ \\
\hline Complications & $10(15.9 \%)$ & $1(2.4 \%)$ & 0.04 \\
\hline Pain & $6(9.5 \%)$ & $1(2.4 \%)$ & 0.24 \\
\hline Infection & $3(4.8 \%)$ & - & 0.27 \\
\hline Thrombus & $4(6.3 \%)$ & - & 0.15 \\
\hline Necrosis & $2(3.2 \%)$ & - & 0.51 \\
\hline
\end{tabular}


In a study by Gebauer, et al., among 299 port catheters inserted with ultrasound guidance, 298 cases of them were placed in jugular vein and 1 case was placed in subclavian vein. In this study, the rate of cannulation success was reported 99\%. No main complication was occurred in these patients. Rate of infection, thrombus and migration were $0.15,0.07$ and 0.04 per 1000 catheter-days, respectively. In general, there were 23 complications (0.33 per 1000 catheter-days). Therefore, results of the study indicated that using ultrasound-guided method is effective in increasing the success rate and decreasing complications [26].

The results of the presented study support priority of ultrasound-guided cannulation in comparison with anatomic landmark method. In this study, the success rate of cannulation with anatomic landmark (96.8\%) was similar to the registered success rate of $85 \%$ - 99\% in the previous studies. Success rate with ultrasound guidance was higher than anatomic landmark method, but this difference was not significant (41 (100\%), 61 (96.8\%), p < 0.518 ), respectively). The results of Froehlich study indicated no significant difference in success rate of cannulation with anatomic landmark (88.2\%) in comparison with ultrasound-guided (90.8\%) [7]. Also, in another study which was fulfilled by Balls in the United States, no significant statistical difference was found in success rate of cannulation between two groups of anatomic landmarks and ultrasound-guided method [15]. However, some of the studies reported different results ([13] [23]-[25] [27]).

In Chuan study which was carried out on 62 infants, the success rate of central vein cannulation with ultrasound guidance $(100 \%)$ and anatomic landmark $(80 \%)$ were statistically significant $(\mathrm{p}<0.05)$ [14]. Some specialists believe that additional equipments and extra retouching related to cannulation with ultrasound guidance might increase rate of complications and infections related to catheter [23]. However, data of the present study and also some other studies did not confirm such belief. In our study, the general rate of complication occurrence for Port-A-Cath implantation in ultrasound-guided group was $0.4 \%$ and in anatomic landmark group was $15.9 \%$, ( $\mathrm{p}<0.04$ ). Many studies have shown that ultrasound guidance will decrease the rate of complication occurrence following central vein cannulation [12] [13] [25]. Karakitsas in a pre-study compared the rate of success and complication occurrence in 450 patients underwent Port-A-Cath implantation with ultrasound guidance, and 450 patients with anatomic landmarks guidance. The success rates of cannulation were $100 \%$ and $94.4 \%$ in ultrasound-guided and anatomical landmark methods, respectively $(\mathrm{p}<0.001)$. In this study, the rate of infection was significantly higher in anatomic landmark group $(\mathrm{p}<0.001)$ [23].

Broad usage of ultrasound in Port-A-Cath insertion has been limited because of inaccessibility to specialized equipments and lack of trained personnel and technical complexity [23] [25]. Therefore, this method technically needs trained operators who have enough experience in operating sonography-guided cannulation [28].

Considering high success rate and low complications of Port-A-Cath placement with ultrasound guidance, we believe that this method is superior to the landmark method in oncologic patients. However, verification of this result requires a prospective randomized trial comparing the two methods.

\section{References}

[1] Brothers, T.E., VonMoll, L.K., Niederhuber, J.E., et al. (1988) Experience with Subcutaneous Infusion Ports in Three Hundred Patients. Surgery, Gynecology \& Obstetrics, 166, 295-301.

[2] Galloway, M. (2010) Insertion and Placement of Central Catheters in the Oncology Patient. Seminars in Oncology Nursing, 26, 102-112. http://dx.doi.org/10.1016/j.soncn.2010.02.004

[3] Tercan, F., Ozkan, U. and Oguzkurt, L. (2008) US-Guided Placement of Central Vein Catheters in Patients with Disorders of Hemostasis. European Journal of Radiology, 65, 253-256. http://dx.doi.org/10.1016/j.ejrad.2007.04.002

[4] Vandonia, R.E., et al. (2009) Randomised Comparison of Complications from Three Different Permanent Central Venous Access Systems. Swiss Medical Weekly, 139, 313-316.

[5] Mumtaz, H., et al. (2001) Central Venous Catheter Placement in Patients with Disorders of Hemostasis. The American Journal of Surgery, 180, 503-506. http://dx.doi.org/10.1016/S0002-9610(00)00552-3

[6] Vescia, S., et al. (2008) Management of Venous Port Systems in Oncology: A Review of Current Evidence. Annals of Oncology, 19, 9-15.

[7] Froehlich, C.D., et al. (2009) Ultrasound-Guided Central Venous Catheter Placement Decreases Complications and Decreases Placement Attempts Compared with the Landmark Technique in Patients in a Pediatric Intensive Care Unit. Pediatric Critical Care, 37, 1090-1096. http://dx.doi.org/10.1097/CCM.0b013e31819b570e

[8] Coccaro, M., Bochicchio, A.M., Capobianco, A.M., Di Leo, P., Mancino, G. and Cammarota, A. (2001) Long-Term Infusional Systems: Complications in Cancer Patients. Tumori, 87, 308-311.

[9] Poorter, R.L., Lauw, F.N., Bemelman, W.A., Bakker, P.J., Taat, C.W. and Veenhof, C.H. (1996) Complications of an 
Implantable Venous Access Device (Port-A-Cath) during Intermittent Continuous Infusion of Chemotherapy. European Journal of Cancer, 32, 2262-2266.

[10] Niederhuber, J.E., Ensminger, W., Gyves, J.W., Liepman, M., Doan, K. and Cozz, E. (1982) Totally Implanted Venous and Arterial Access System to Replace External Catheters in Cancer Treatment. Surgery, 92, 706-711.

[11] Ku, Y., Kuo, P., Tsai, Y., Huang, W., Lin, M. and Tsao, C. (2009) Port-A-Cath Implantation Using Percutaneous Puncture without Guidance. Annals of Surgical Oncology, 16, 729-734. http://dx.doi.org/10.1245/s10434-008-0224-4

[12] Palepu, G.B., Deven, J., Subrahmanyam, M. and Mohan, S. (2009) Impact of Ultrasonography on Central Venous Catheter Insersion in Intensive Care. Indian Journal of Radiology and Imaging, 19, 3.

[13] Arul, G.S., Lewis, N., Bromley, P. and Bennett, J. (2009) Ultrasound-Guided Percutaneous Insertion of Hickman Lines in Children. Prospective Study of 500 Consecutive Procedures. Journal of Pediatric Surgery, 44, 1371-1376. http://dx.doi.org/10.1016/j.jpedsurg.2008.12.004

[14] Chuan, W., Wei, W. and Yu, I. (2005) A Randomized-Controlled Study of Ultrasound Prelocation vs Anatomical Landmark-Guided Cannulation of the Internal Jugular Vein in Infants and Children. Paediatric Anaesthesia, 15, 733738.

[15] Balls, A., LoVecchio, F., Kroeger, A., Stapczynski, J.S., Mulrow, M. and Drachman, D. (2010) Ultrasound Guidance for Central Venous Catheter Placement: Results from the Central Line Emergency Access Registry Database. American Journal of Emergency Medicine, 28, 561-567. http://dx.doi.org/10.1016/j.ajem.2009.02.003

[16] Gallieni, M., Pittiruti, M. and Biffi, R. (2008) Vascular Access in Oncology Patients. CA: A Cancer Journal for Clinicians, 58, 323-346. http://dx.doi.org/10.3322/CA.2008.0015

[17] Kusminsky, R.E. (2007) Complications of Central Venous Catheterization. Journal of the American College of Surgeons, 204, 681-696.

[18] Lewis, C.A., et al. (2003) Quality Improvement Guidelines for Central Venous Access. Journal of Vascular and Interventional Radiology, 14, 231-235.

[19] Beckers, M., Ruven, H., Seldenrijk, C.A., Prins, M.H. and Biesma, D.H. (2010) Risk of Thrombosis and Infections of Central Venous Catheters and Totally Implanted Access Ports in Patients Treated for Cancer. Thrombosis Research, 125, 318-321. http://dx.doi.org/10.1016/j.thromres.2009.06.008

[20] Nosher, J.L., et al. (2001) Radiologic Placement of a Low Profile Implantable Venous Access Port in a Pediatric Population. Cardio Vascular and Interventional Radiology, 24, 395-399. http://dx.doi.org/10.1007/s00270-001-0071-1

[21] Yip, D. and Funaki, B. (2002) Subcutaneous Chest Ports via the Internal Jugular Vein. Acta Radiologica, 43, 371-375. http://dx.doi.org/10.1034/j.1600-0455.2002.430405.x

[22] Gebauer, B., Teichgräber, U., Werk, M., Beck, A. and Wagner, H. (2008) Sonographically Guided Venous Puncture and Fluoroscopically Guided Placement of Tunneled, Large-Bore Central Venous Catheters for Bone Marrow Transplantation-High Success Rates and Low Complication Rates. Supportive Care in Cancer, 16, 897-904. http://dx.doi.org/10.1007/s00520-007-0378-9

[23] Karakitsos, D., et al. (2006) Real-Time Ultrasound-Guided Catheterization of the Internal Jugular Vein: A Prospective Comparison with the Landmark Technique in Critical Care Patients. Critical Care, 10, 6.

[24] Koroglu, M., et al. (2006) Percutaneous Placement of Central Venous Catheters: Comparing the Anatomical Landmark Method with the Radiologically Guided Technique for Central Venous Catheterization through the Internal Jugular Vein in Emergent Hemodialysis Patients. Acta Radiologica, 47, 43-47. http://dx.doi.org/10.1080/02841850500406845

[25] Denys, B.G., Uretsky, B.F. and Reddy, P.S. (1993) Ultrasound-Assisted Cannulation of the Internal Jugular Vein. A Prospective Comparison to the External Landmark-Guided Technique. Circulation, 87, 1557-1562. http://dx.doi.org/10.1161/01.CIR.87.5.1557

[26] Gebauer, B., El-Sheik, M., Vogt, M. and Wagner, H. (2009) Combined Ultrasound and Fluoroscopy Guided Port Catheter Implantation-High Success and Low Complication Rate. European Journal of Radiology, 69, 517-522. http://dx.doi.org/10.1016/j.ejrad.2007.10.018

[27] Miller, A.H., Roth, B.A., Mills, T.J., Woody, J.R., Longmoor, C.E. and Foster, B. (2002) Ultrasound Guidance versus the Landmark Technique for the Placement of Central Venous Catheters in the Emergency Department. Academic Emergency Medicine, 9, 800-805. http://dx.doi.org/10.1111/j.1553-2712.2002.tb02168.x

[28] McGee, D.C. and Gould, M.K. (2003) Preventing Complications of Central Venous Catheterization. The New England Journal of Medicine, 348, 1123-1133. 